\title{
Clinical outcome following second-generation drug-eluting stent use for off-label versus on-label indications: insights from the two-year outcome of the TWENTE trial
}

\author{
Hanim Sen ${ }^{1}$, MD; Ming Kai Lam¹, MD; Kenneth Tandjung ${ }^{1}$, MD, PhD; Mounir W.Z. Basalus ${ }^{1}$, MD, PhD; \\ Frits H.A.F. de Man $^{1}$, MD, PhD; J. Hans W. Louwerenburg ${ }^{1}$, MD; Martin G. Stoel ${ }^{1}$, MD, PhD; \\ Gert K. van Houwelingen ${ }^{1}$, MD; Marije M. Löwik¹, PhD; Gerard C.M. Linssen², MD, PhD; \\ Salah A.M. Saïd ${ }^{2}$, MD, PhD; Mark B. Nienhuis ${ }^{3}$, MD, PhD; Patrick M.J. Verhorst ${ }^{1}, \mathrm{MD}, \mathrm{PhD}$; \\ Job van der Palen ${ }^{4,5}, \mathrm{PhD}$; Clemens von Birgelen ${ }^{1,6 *}, \mathrm{MD}, \mathrm{PhD}$
}

\section{Department of Cardiology, Thoraxcentrum Twente, Medisch Spectrum Twente, Enschede, The Netherlands; 2. Department of Cardiology, Ziekenhuisgroep Twente, Almelo and Hengelo, The Netherlands; 3. Department of Cardiology, Streekziekenhuis Koningin Beatrix, Winterswijk, The Netherlands; 4. Department of Epidemiology, Medisch Spectrum Twente, Enschede, The Netherlands; 5. Department of Research Methodology, Measurement and Data Analysis, University of Twente, Enschede, The Netherlands; 6. Health Technology and Services Research, MIRA - Institute for Biomedical Technology and Technical Medicine, University of Twente, Enschede, The Netherlands}

H. Sen and M.K. Lam contributed equally to this manuscript.

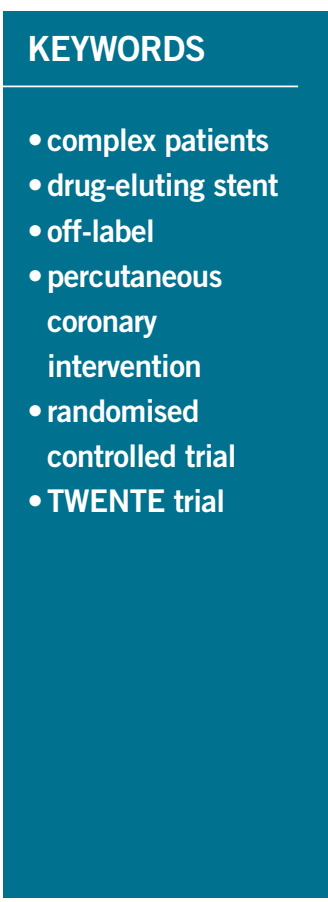

\begin{abstract}
Aims: Drug-eluting stents (DES) were first used on-label - in simple patients with low clinical risk and easily accessible lesions. Currently, DES are increasingly used off-label - in complex patients undergoing percutaneous coronary interventions (PCI) with historically higher event risk. Therefore, our aim was to investigate whether patients with off-label indications for DES use had similar outcomes compared to patients who were treated for on-label indications only.
\end{abstract}

Methods and results: We analysed two-year follow-up data of 1,387 TWENTE trial patients, treated with second-generation everolimus-eluting XIENCE V or zotarolimus-eluting Resolute stents, and compared offlabel vs. on-label DES use with regard to the following clinical endpoints: cardiac death, myocardial infarction (MI), periprocedural MI ( $\leq 48 \mathrm{hrs})$, and target vessel revascularisation (TVR). Patients with off-label DES use $(n=1,033 ; 74.5 \%)$ had more diabetes $(22.9 \%$ vs. $17.5 \%$; $=0.032)$, previous MI (35.9\% vs. $22.3 \%$; $\mathrm{p}<0.001)$, type B2/C lesions ( $84.7 \%$ vs. $62.7 \%$; $<<0.001)$, and acute coronary syndromes ( $57.8 \%$ vs. $33.3 \%$; $\mathrm{p}<0.001)$. Nevertheless, cardiac death and TVR rates were similar to those of patients with on-label DES use ( $p>0.8$ ). Following off-label DES use, there was a higher incidence of PMI (5.0\% vs. 1.4\%; $p=0.003)$, of which only $1.1 \%$ reached creatine kinase levels $>5 \mathrm{x}$ the upper limit of normal (ULN).

Conclusions: Despite differences in risk profile, patients with off-label DES use did not differ from patients with on-label DES use in clinical endpoints other than periprocedural MI. These largely positive findings underline the favourable safety profile of second-generation DES.

*Corresponding author: Department of Cardiology, Thoraxcentrum Twente, Medisch Spectrum Twente, Haaksbergerstraat 55, 7513 ER Enschede, The Netherlands.E-mail: c.vonbirgelen@mst.nl 


\section{Abbreviations}

$\begin{array}{ll}\text { ACS } & \text { acute coronary syndromes } \\ \text { DES } & \text { drug-eluting stent } \\ \text { MI } & \text { myocardial infarction } \\ \text { NSTE-ACS } & \text { non-ST-elevation acute coronary syndromes } \\ \text { PCI } & \text { percutaneous coronary intervention } \\ \text { STEMI } & \text { ST-elevation myocardial infarction } \\ \text { TVR } & \text { target vessel revascularisation }\end{array}$

\section{Introduction}

Initially, drug-eluting stents (DES) were intended to be implanted onlabel during percutaneous coronary interventions (PCI) in easily accessible lesions of low-risk patients ${ }^{1}$. Shortly thereafter, DES were increasingly used off-label in patients who were characterised by a higher clinical event risk and more challenging lesion anatomies ${ }^{2}$. Nevertheless, in routine clinical procedures with more off-label use of first-generation DES, event rates were higher than in the initial pivotal trials ${ }^{3}$. Patients with offlabel use of first-generation DES had a higher risk of death, myocardial infarction (MI), stent thrombosis (ST), and repeat revascularisation procedures than patients with on-label DES use ${ }^{3,4}$.

Second-generation DES with more biocompatible coatings ${ }^{5}$ were developed to improve outcome and counteract the drawbacks of the early-generation DES. The Resolute zotarolimus-eluting stent (ZES) (Medtronic Cardiovascular, Santa Rosa, CA, USA) and the XIENCE $V^{\circledR}$ everolimus-eluting stent (EES) (Abbott Vascular, Santa Clara, CA, USA) are two widely used second-generation DES, for which similar safety and efficacy have been demonstrated in the randomised RESOLUTE All Comers and TWENTE trials, which enrolled patients with off-label DES use in two thirds and three quarters of their study populations, respectively ${ }^{6,7}$. So far, most data on clinical outcome following the use of second-generation DES for off-label indications have been derived from registries $^{8-10}$. In particular, outcome data beyond one year were scarce ${ }^{11}$. In a substudy of the prospective TWENTE trial ${ }^{7,12}$, we investigated whether patients with off-label indications for DES use had a similar two-year clinical outcome as compared to patients who were treated for on-label indications only.

\section{Methods}

\section{STUDY DESIGN AND PATIENT POPULATION}

Details of the randomised TWENTE trial, which was performed between June 18, 2008, and August 26, 2010, at the Thoraxcentrum Twente in Enschede, The Netherlands, have previously been reported $^{7}$. In brief, TWENTE (ClinicalTrials.gov NCT01066650) was a randomised, controlled, patient-blinded DES trial, comparing Resolute ZES and XIENCE V EES stents after 1:1 randomisation in 1,391 patients. Patients with non-ST-elevation acute coronary syndromes (NSTE-ACS) or stable angina were eligible, and few exclusion criteria were applied ${ }^{7}$. In TWENTE, a total of $81.4 \%$ of all eligible patients were enrolled, of whom more than $52 \%$ presented with ACS. The real-world character of the randomised TWENTE trial was underlined by the findings of the non-enrolled TWENTE study, which demonstrated similar and excellent outcomes of the eligible but non-enrolled patients ${ }^{13}$. The present study population consisted of 1,387 patients (four patients withdrew consent) ${ }^{7}$.

Off-label indications for DES use were defined as: renal insufficiency (serum creatine level $\geq 140 \mu \mathrm{mol} / \mathrm{L}$ ); ejection fraction $<30 \%$; occurrence of acute MI within the previous 72 hours; more than one lesion/vessel; more than two vessels treated; lesion length $>27 \mathrm{~mm}$; bifurcation; saphenous vein graft lesion; arterial bypass graft lesion; in-stent restenosis; unprotected left main lesion; lesion with thrombus; and/or lesion with total occlusion.

\section{INTERVENTION, ELECTROCARDIOGRAPHY, LABORATORY TESTING, AND ANGIOGRAPHIC ANALYSIS}

Five experienced interventional cardiologists, each of whom had individual experience of at least 4,000 PCI procedures, performed all the PCI procedures of the TWENTE trial using standard techniques. Periprocedural pharmacological as well as systematic laboratory testing and ECG assessment have previously been described $^{7}$. Quantitative coronary angiography analyses were performed offline with QAngio XA version 7.1 (Medis medical imaging sytems bv, Leiden, The Netherlands).

\section{CLINICAL ENDPOINTS}

Definitions of clinical endpoints were reported on a patient level, as previously described in detail ${ }^{7}$, and generally followed the suggestions of the Academic Research Consortium (ARC) ${ }^{14,15}$. Death was considered cardiac unless an unequivocal non-cardiac cause could be established. MI was defined by any creatine kinase concentration of more than twice the upper limit of normal (ULN) with elevated confirmatory cardiac biomarkers ${ }^{14}$. Further classification and location of MI was based on laboratory testing, electrocardiographic parameters, angiographic information, and clinical data ${ }^{7}$. MI was classified as target vessel-related if related to the target vessel or if it could not be related to another vessel. Target vessel revascularisation (TVR) and target lesion revascularisation (TLR) by re-PCI or surgery were considered clinically indicated if the angiographic diameter stenosis was $\geq 70 \%$, or $\geq 50 \%$ in the presence of ischaemic signs or symptoms ${ }^{15}$. Stent thrombosis was defined according to $\mathrm{ARC}^{15}$.

\section{DATA ACQUISITION, FOLLOW-UP, AND CLINICAL EVENT ADJUDICATION}

Two-year follow-up data were available in $100 \%$ of patients. For any event trigger, clinical information was gathered from the referring cardiologist, general practitioner, and/or hospital involved. This was facilitated by a close network of cooperation between the care providers in the Twente region. The processing of clinical data and adjudication of adverse clinical events were performed by an independent, external contract research organisation and core laboratory (Cardialysis, Rotterdam, The Netherlands), which also performed an on-site audit to assess key study data.

\section{STATISTICAL ANALYSIS}

Data analysis was performed with the Statistical Package for Social Sciences (SPSS) version 17 (SPSS Inc., Chicago, IL, USA). 
Data were reported as frequencies and percentages for dichotomous and categorical variables and as mean \pm SD for continuous variables. Chi-square and Fisher's exact tests were used as appropriate. The Student's t-test was used to test normally distributed parameters. The Kaplan-Meier method was used to calculate the time to clinical endpoints, and the log-rank test was used to compare betweengroup differences. Possible predictors of periprocedural myocardial infarction (PMI) were identified if $p$-values were $<0.15$ at univariate analysis of the relation between the variables of the definition of off-label versus PMI. A multivariate Cox regression analysis was then performed to evaluate the independent predictors of PMI. Two-sided p-values $<0.05$ were considered significant.

\section{Results}

\section{CHARACTERISTICS OF PATIENTS, LESIONS, AND PCI PROCEDURES}

Of the entire population of the TWENTE trial, 1,033 (74.5\%) patients were treated with DES for at least one off-label indication, and $354(25.5 \%)$ were treated for on-label indications only (Table 1). Patients with off-label DES use had a slightly higher prevalence of diabetes mellitus $(22.9 \%$ vs. $17.5 \%$; $=0.032)$ and chronic renal failure $(3.3 \%$ vs. $1.1 \%$; $=0.032)$, and significantly more often a history of MI (35.9\% vs. $22.3 \%$; p $<0.001)$, NSTE$\mathrm{ACS}$ at presentation ( $57.8 \%$ vs. $33.3 \%$; $<<0.001)$, and more $\mathrm{B} 2 / \mathrm{C}$ lesion types $(84.7 \%$ vs. $62.7 \%$; $<<0.001)$. Between patients with off-label versus on-label DES use, there were significant differences in various angiographic and procedural details which were mainly related to the definition of the groups. In addition, in patients with off-label DES use there were more ostial $(12.2 \%$ vs. $7.3 \% ; \mathrm{p}=0.012)$ and severely calcified lesions (21.0\% vs. $16.1 \%$; $\mathrm{p}=0.045)$, and stent post-dilation was more often performed $(90.4 \%$ vs. $80.2 \%$; $<0.001)$.

\section{CLINICAL OUTCOME}

Two-year follow-up data were available in 1,387 patients. The rates of death from any cause ( $4.5 \%$ vs. $4.2 \% ; \mathrm{p}=0.806)$, cardiac death ( $2.1 \%$ vs. $2.3 \% ; p=0.884)$, TVR $(5.4 \%$ vs. $5.1 \% ; p=0.808)$, and definite or probable stent thrombosis $(1.4 \%$ vs. $1.1 \%$; $=1.0)$ were similar for patients with off-label and on-label DES use (Table 2). There was a difference in the incidence of target vessel-related MI (6.4\% vs. $2.8 \% ; \mathrm{p}=0.011)$. While the rate of target vessel-related MI $>48$ hours was similar for both groups ( $1.4 \%$ vs. $1.4 \%$; $p=1.0)$, the rate of target vessel-related $\mathrm{MI} \leq 48$ hours (i.e., PMI) was significantly higher in patients with off-label DES use (5.0\% vs. 1.4\%; $\mathrm{p}=0.003$ ), of which $1.1 \%$ developed a maximum creatine kinase level $>5 \mathrm{x}$ ULN (Table 2).

Figure 1 shows the Kaplan-Meier cumulative incidence of three major clinical endpoints: cardiac death, target vessel-related MI, and TVR. Of these three endpoints, only target vessel-related MI showed a significantly higher rate in patients with off-label DES use ( $\mathrm{p} \log$-rank=0.011). Figure 2 displays the cumulative incidence of target vessel-related MI within $\leq 48$ hours (i.e., PMI) as well as after $>48$ hours (i.e., non-PMI), showing that only MI after
Table 1. Characteristics of patients and procedures.

\begin{tabular}{|c|c|c|c|}
\hline & $\begin{array}{c}\text { Off-label } \\
(n=1,033)\end{array}$ & $\begin{array}{l}\text { On-label } \\
(n=354)\end{array}$ & $p$-value \\
\hline Age, yrs & $64.4 \pm 10.7$ & $64.0 \pm 10.2$ & 0.507 \\
\hline Men & $752(72.8)$ & $253(71.5)$ & 0.629 \\
\hline BMI $\left(\mathrm{kg} / \mathrm{m}^{2}\right)$ & $27.7 \pm 3.9$ & $27.9 \pm 4.2$ & 0.360 \\
\hline Diabetes mellitus (any) & $237(22.9)$ & $62(17.5)$ & 0.032 \\
\hline Chronic renal failure* & $34(3.3)$ & $4(1.1)$ & 0.032 \\
\hline Arterial hypertension & $558(54.0)$ & $213(60.2)$ & 0.044 \\
\hline Hypercholesterolaemia & $577 / 1,004(57.5)$ & $224 / 349(64.2)$ & 0.028 \\
\hline Current smoker & $265(25.7)$ & $75(21.2)$ & 0.092 \\
\hline Family history of CAD & $537(52.0)$ & $200(56.5)$ & 0.142 \\
\hline Myocardial infarction (any) & $371(35.9)$ & 79 (22.3) & $<0.001$ \\
\hline Previous PCI & $217(21.0)$ & $70(19.8)$ & 0.621 \\
\hline Previous CABG & $116(11.2)$ & $32(9.0)$ & 0.249 \\
\hline Clinical characteristic & & & $<0.001$ \\
\hline Stable angina pectoris & $436(42.2)$ & $236(66.7)$ & \\
\hline Acute coronary syndrome & $597(57.8)$ & 118 (33.3) & \\
\hline Unstable angina & $214(20.7)$ & $111(31.4)$ & \\
\hline Non-ST-elevation MI & $383(37.1)$ & $7(2.0)$ & \\
\hline Left ventricular ejection fraction $<30 \% \pi$ & $32 / 792(4.0)$ & 0 & 0.001 \\
\hline Multivessel treatment & $281(27.2)$ & $53(15.0)$ & $<0.001$ \\
\hline Total no. of lesions treated per patient & & & $<0.001$ \\
\hline 1 lesion treated & $549(53.1)$ & $307(86.7)$ & \\
\hline 2 lesions treated & $344(33.3)$ & $47(13.3)$ & \\
\hline 3 or more lesions treated & $140(13.6)$ & 0 & \\
\hline De novo coronary lesions only & $930(90.0)$ & $354(100.0)$ & $<0.001$ \\
\hline At least 1 CTO & $95(9.2)$ & 0 & $<0.001$ \\
\hline Severe calcification & $217(21.0)$ & $57(16.1)$ & 0.045 \\
\hline Aorta ostial lesion & $126(12.2)$ & $26(7.3)$ & 0.012 \\
\hline At least 1 bifurcation & $362(35.0)$ & 0 & $<0.001$ \\
\hline At least 1 bifurcation with SB treatment ${ }^{\ddagger}$ & $213(20.6)$ & 0 & $<0.001$ \\
\hline At least 1 in-stent restenosis & $68(6.6)$ & 0 & $<0.001$ \\
\hline At least $1 \mathrm{small}$ vessel (RVD <2.75 mm) & $657(63.6)$ & $215(60.7)$ & 0.335 \\
\hline At least 1 lesion length $>27 \mathrm{~mm}$ & $293(28.4)$ & 0 & $<0.001$ \\
\hline Glycoprotein Ilb/llla antagonist & $175(16.9)$ & $18(5.1)$ & $<0.001$ \\
\hline \multicolumn{4}{|l|}{ Target coronary artery } \\
\hline Left main & $43(4.2)$ & $9(2.5)$ & 0.166 \\
\hline Left anterior descending & $551(53.3)$ & $172(48.6)$ & 0.122 \\
\hline Left circumflex & $326(31.6)$ & $111(31.4)$ & 0.944 \\
\hline Right coronary artery & $387(37.5)$ & $115(32.5)$ & 0.093 \\
\hline Bypass graft & $41(4.0)$ & 0 & $<0.001$ \\
\hline ACC-AHA lesion class ${ }^{\S}$ & & & $<0.001$ \\
\hline A & $25(2.4)$ & $39(11.0)$ & \\
\hline B1 & $133(12.9)$ & $93(26.3)$ & \\
\hline B2 & $280(27.1)$ & $129(36.4)$ & \\
\hline$C$ & $595(57.6)$ & $93(26.3)$ & \\
\hline Post-dilation & $934(90.4)$ & $284(80.2)$ & $<0.001$ \\
\hline
\end{tabular}

Data are number (\%) or mean (SD). *Chronic renal failure was defined by serum creatinine level $\geq 130 \mu \mathrm{mol} / \mathrm{L}$. "Left ventricular ejection fraction was assessed with ultrasound, MRI or LV angiography. ${ }^{\ddagger}$ SB: side branch. ${ }^{\S}$ Highest lesion classification. ACC-AHA: American College of Cardiology/American Heart Association; BMI: body mass index; CABG: coronary artery bypass grafting; CAD: coronary artery disease; CTO: chronic total occlusion; MI: myocardial infarction; PCl: percutaneous coronary intervention; RVD: reference vessel diameter 
Table 2. Clinical outcome after two years.

\begin{tabular}{|c|c|c|c|}
\hline & $\begin{array}{c}\text { Off-label } \\
(n=1,033)\end{array}$ & $\begin{array}{l}\text { On-label } \\
(n=354)\end{array}$ & $p$-value \\
\hline Death, any cause & $47(4.5)$ & $15(4.2)$ & 0.806 \\
\hline Death, cardiac cause & $22(2.1)$ & $8(2.3)$ & 0.884 \\
\hline Target vessel-related MI & $66(6.4)$ & $10(2.8)$ & 0.011 \\
\hline CK $>2$ ULN * & $66(6.4)$ & $10(2.8)$ & 0.011 \\
\hline CK >3 ULN & $22(2.1)$ & $3(0.8)$ & 0.118 \\
\hline CK $>5$ ULN & $11(1.1)$ & - & 0.076 \\
\hline $\mathrm{PMI}$ (MI $\leq 48$ hrs) & $52(5.0)$ & $5(1.4)$ & 0.003 \\
\hline $2<\mathrm{CK} \leq 5 \mathrm{ULN}$ & $41(4.0)$ & $5(1.4)$ & 0.024 \\
\hline CK >5 ULN & $11(1.1)$ & 0 & 0.076 \\
\hline Non-PMI (MI >48 hrs) & $14(1.4)$ & $5(1.4)$ & 1.0 \\
\hline Revascularisation, any & $99(9.6)$ & $28(7.9)$ & 0.346 \\
\hline Target lesion revascularisation (TLR) & $43(4.2)$ & $9(2.5)$ & 0.166 \\
\hline Target vessel revascularisation (TVR) $)^{\pi}$ & $56(5.4)$ & $18(5.1)$ & 0.808 \\
\hline \multicolumn{4}{|l|}{ Definite ST (0-720 days) } \\
\hline All patients & $5(0.5)$ & $2(0.6)$ & 1.0 \\
\hline \multicolumn{4}{|l|}{ Probable ST (0-720 days) } \\
\hline All patients & $9(0.9)$ & $2(0.6)$ & 0.739 \\
\hline \multicolumn{4}{|l|}{ ST (0-720 days) } \\
\hline Possible & $11(1.1)$ & $5(1.4)$ & 0.571 \\
\hline Definite or probable & $14(1.4)$ & $4(1.1)$ & 1.0 \\
\hline $\begin{array}{l}\text { Very late definite or probable ST ( } 360-720 \\
\text { days) }\end{array}$ & $2(0.2)$ & $2(0.6)$ & 0.270 \\
\hline
\end{tabular}

Data are number of patients (\%). * In our study, MI was defined by any creatine kinase (CK) concentration of more than double the upper limit of normal (ULN) with elevated values of a confirmatory cardiac biomarker. "TVR and TLR were clinically indicated. MI: myocardial infarction; PMI: periprocedural MI; ST: stent thrombosis

$\leq 48$ hours occurred significantly more often in patients with offlabel DES use ( $\mathrm{p} \log$-rank $=0.003$ ).

\section{IDENTIFICATION OF POSSIBLE PREDICTORS}

The chi-square test was applied to identify independent predictors of PMI. The following variables of the definition of off-label showed a univariate association $(\mathrm{p}<0.15)$ with PMI, and were further evaluated: treatment of more than one lesion/vessel, more than two vessels, lesion length $>27 \mathrm{~mm}$, bifurcation lesion; and lesion with thrombus.

\section{MULTIVARIATE COX REGRESSION ANALYSIS}

Lesion length $>27 \mathrm{~mm}$ (adjusted HR 2.84, 95\% CI: 1.68-4.80, $\mathrm{p}<0.001$ ), more than one lesion/vessel (adjusted HR 2.55, 95\% CI: 1.51-4.32, $<<0.001$ ), and bifurcation lesion (adjusted HR 2.03, 95\% CI: $1.20-3.45, p=0.008$ ) were the only significant independent predictors of PMI which were related to the definition of off-label DES use.

\section{Discussion}

In the TWENTE trial, off-label DES use was associated with more clinical, lesion, and procedure-related characteristics of increased risk, as might have been expected from the definition of off-label
A

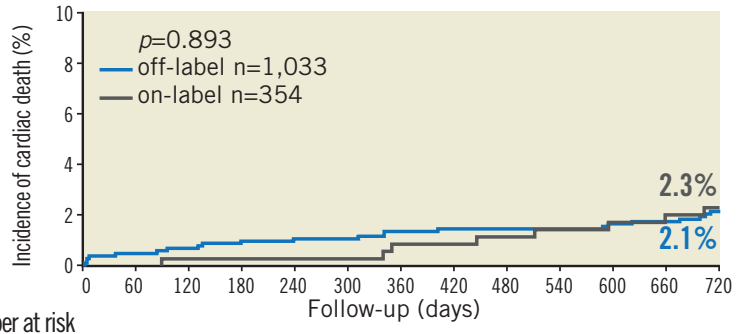

Number at risk

$\begin{array}{llllllllllllllll}\text { Off-label } & 1,033 & 1,027 & 1,020 & 1,016 & 1,015 & 1,014 & 1,010 & 1,009 & 1,005 & 1,003 & 995 & 994 & 962\end{array}$ On-label $\quad \begin{array}{lllllllllllll}354 & 354 & 353 & 353 & 353 & 351 & 348 & 347 & 346 & 344 & 343 & 341 & 325\end{array}$

B

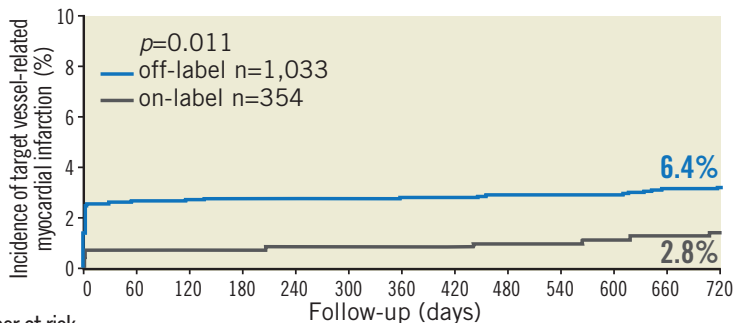

Number at risk

$\begin{array}{llllllllllllll}\text { Off-label } & 1,033 & 974 & 967 & 963 & 962 & 961 & 957 & 956 & 950 & 948 & 941 & 936 & 905\end{array}$ $\begin{array}{llllllllllllll}\text { On-label } & 354 & 349 & 348 & 348 & 347 & 345 & 342 & 341 & 339 & 337 & 335 & 332 & 316\end{array}$

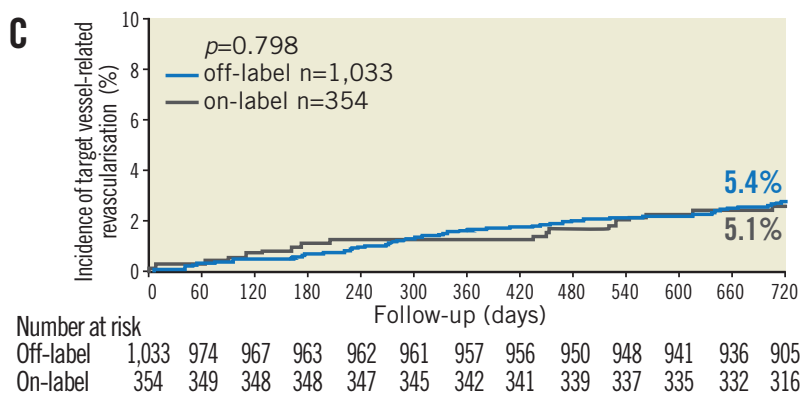

Figure 1. Kaplan-Meier curves for cardiac death, target vesselrelated MI, and TVR. Kaplan-Meier cumulative incidence curves at two years for: A) cardiac death; B) target vessel-related MI; and C) target vessel revascularisation for patients treated with off-label and on-label DES use.

DES use. In addition, PCI was more often driven by ACS, which triggered the use of glycoprotein IIb/IIIa antagonists in a higher proportion of patients. Despite this significant difference in risk

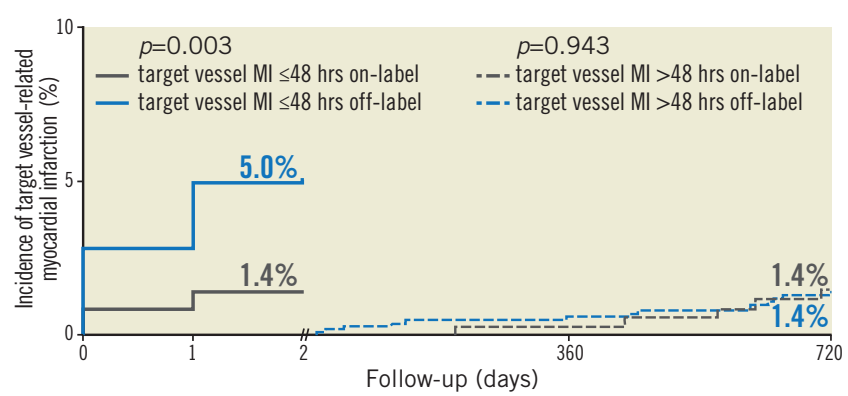

Figure 2. Target vessel-related $M I \leq 48$ hours (periprocedural) and $>48$ hours. Kaplan-Meier cumulative incidence curves at two years for (left) target vessel-related $M I \leq 48$ hours and (right) target vessel-related $M I>48$ hours for patients treated with off-label and on-label DES use. 
profile, both patient groups showed low and similar two-year rates of various clinical endpoints, such as death from any cause, cardiac death, target vessel revascularisation, and definite or probable stent thrombosis. The only exception was a higher incidence of PMI (i.e., $\mathrm{MI} \leq 48$ hours following PCI) in patients with off-label DES use, of whom only a minority developed a myocardial necrosis with a maximum CK level of more than five times the upper limit of normal. These findings underline the favourable safety profile of secondgeneration DES.

In this analysis, there was no difference in target vessel-related MI after more than 48 hours between patients with off-label and on-label DES use $(1.4 \%$ vs. $1.4 \%)$; there was a higher rate of (periprocedural) target-vessel-related MI in patients with off-label DES use (5.0\% vs. $1.4 \%)$ only within the first 48 hours after PCI. Such PMI typically results from microembolisation of plaque material, or stent-induced closure of small side branches, which occurs more frequently in patients with ACS and in extensive coronary disease ${ }^{16,17}$. In the present analysis, the higher incidence of PMI following off-label DES use led to a higher rate of target vessel-related MI during two years of follow-up (6.4\% vs. $2.8 \%$, respectively).

\section{COMPARISON WITH PREVIOUS STUDIES}

Off-label use of first-generation DES was previously shown to be associated with a higher risk of death, MI, and/or repeat revascularisation procedures ${ }^{3,4,17,18}$. Detailed analyses of clinical outcome following off-label use of second-generation DES were performed in a few studies only ${ }^{8-11}$. Latib et al reported a retrospective analysis of patients treated with XIENCE V EES (248 [72\%] off-label) and a median follow-up of 12 months $^{8}$. Galasso et al and Romagnoli et al published two registries of patients treated with Resolute ZES (311 [84\%] and 504 [61\%] off-label) and an average followup duration of 17 and 12 months, respectively ${ }^{9,10}$. Stefanini et al reported data from the only randomised study - the RESOLUTE All Comers trial - which compared 12-month clinical outcome of patients treated with Resolute ZES and XIENCE V EES in 1,520 (66.3\%) complex patients (with off-label DES use) versus $(33.7 \%)$ simple patients ${ }^{11}$. Our present analysis of the randomised TWENTE trial, which included 1,033 (74.5\%) patients with off-label DES use, is the first comprehensive analysis of 24-month follow-up data to compare the clinical outcome of patients treated for off-label and on-label indications with either Resolute ZES or XIENCE V EES.

In the RISICO registry, Romagnoli et al found no significant difference in the incidence of in-hospital MI between off-label and on-label treatment with Resolute ZES (3.8 vs. $2.5 \%$, respectively; $\mathrm{p}=0.4)^{10}$. While the RISICO registry defined MI by the elevation of creatine kinase or creatine kinase-MB levels to $\geq 3$ times the upper limit of normal ${ }^{10}$, in the TWENTE trial MI was defined by CK levels $\geq 2$ times the upper limit of normal with elevated confirmatory cardiac biomarkers ${ }^{7}$. This may partly explain the slightly higher incidence of PMI (5.0\%) in TWENTE patients with off-label DES use. The TWENTE trial compared the same DES types as RESOLUTE All Comers, and also evaluated DES use in daily clinical practice within a slightly different population which did not include acute STEMI. Using the same criteria of off-label DES use, the proportion of complex patients was somewhat higher in the TWENTE trial $(74.5 \%$ vs. $66.3 \% ; \mathrm{p}<0.001)$. Nevertheless, it is difficult to compare the outcome results of both trials as the corresponding subgroup analysis of RESOLUTE All Comers focused on stent level comparisons ${ }^{11}$. While all-comer DES trials generally comprise relatively low rates of PCI for unprotected left main lesions, which is one of the off-label criteria, the ISAR-LEFT MAIN 2 study recently reported in 650 patients treated with Resolute and XIENCE V stents for unprotected left main lesions a favourable outcome at one-year follow-up ${ }^{19}$.

In the four-year follow-up data of the LEADERS study, a subgroup analysis of the primary composite endpoint TVF favours the biolimus-eluting BioMatrix stent with biodegradable polymer coating (Biosensors Inc., Newport Beach, CA, USA) over the first-generation sirolimus-eluting CYPHER ${ }^{\circledR}$ stent with biodurable coating (Cordis, Johnson \& Johnson, Warren, NJ, USA) in patients treated for off-label indications ${ }^{20}$. Nevertheless, only limited individual outcome data of patients treated with DES with biodegradable coatings for off-label versus on-label indications have been reported. In the NOBORI 2 study, which comprised 2,242 patients treated with the biolimus-eluting Nobori stent with biodegradable coating (Terumo Medical Corp., Tokyo, Japan) for at least one off-label indication, off-label stent use was associated with higher rates of cardiac death ( $1.9 \%$ vs. $0.7 \%, \mathrm{p}=0.02)$, TVR $(5.1 \%$ vs. $2.3 \%, \mathrm{p}<0.01)$, and MI $(2.7 \% \text { vs. } 1.5 \%, p=0.04)^{21}$. In addition, in that study there was no significant difference in the rate of definite or probable stent thrombosis between patients with off-label versus on-label DES use ${ }^{21}$.

In the present study, we also found a higher rate of MI in offlabel patients, and there was no significant difference in stent thrombosis between patients with off-label versus on-label indications. Our findings differ from NOBORI 2 with regard to cardiac death and TVR, which were similar for our off-label and on-label patients. Due to differences in patient population and limitations inherent to the study design, it may be difficult to compare the findings of registries and randomised trials. In addition, we post-dilated stents in $90.4 \%$ and $80.2 \%$ of the off-label and on-label patients, respectively $(\mathrm{p}<0.001)$, while in the NOBORI 2 study post-dilation was only performed in $34.9 \%$ and $31.5 \%$, respectively ( $\mathrm{p}=0.07)$, of both patient groups ${ }^{21}$. Substantial differences in material (stainless steel vs. cobalt-chromium) and strut thickness (relatively thick struts vs. thinner struts) of the stent platforms might also have contributed to differences in certain outcome parameters between both studies.

\section{PERIPROCEDURAL MYOCARDIAL INFARCTION}

In our analysis, target vessel-related $\mathrm{MI} \leq 48$ hours following PCI was the only clinical endpoint which was significantly higher in patients with off-label DES use. In fact, many criteria of off-label DES use characterise patients with an advanced stage of coronary disease with greater atherosclerotic burden and more complex lesions ${ }^{8}$. Such patients often require stenting of multiple 
lesions with more aggressive interventional treatment which often includes stent post-dilation with high balloon pressures ${ }^{7}$. In addition, greater atheroma volumes and complex lesion morphologies bear a greater risk of significant microembolisation of plaque or thrombi, which can lead to myocardial injury and $\mathrm{PMI}^{16}$. PMI is frequently a marker of atherosclerotic burden and of the complexity of the interventional procedure ${ }^{16}$. It has previously been related to an increased mortality during short-term and long-term followup after $\mathrm{PCI}^{22-25}$, while other studies showed no significant relation between PMI and clinical outcome ${ }^{26,27}$. In fact, the extent of cardiac marker release may be relevant, as an impact on prognosis may be more likely in the presence of large $\mathrm{PMI}^{16}$. In the present analysis the vast majority of patients with PMI had no more than moderate PMI with maximum CK levels between $2 x$ the ULN and $5 \mathrm{x}$ the ULN.

In our study, off-label patients had relatively low cardiovascular event rates. Several factors might have contributed to this phenomenon. First, the improved flexibility of the cobalt-chromium-based stents, the more biocompatible coatings of second-generation DES, and improvement of other procedural devices (e.g., balloon catheters, guidewires) may have played a role. Secondly, the high postdilatation rate of $88 \%$ may have improved DES apposition which might have contributed to the overall favourable findings. Thirdly, the modification of adjunctive medication and the increased awareness of the importance of dual antiplatelet therapy continuation by various healthcare providers may also have played a role in improving clinical outcome of DES in our present study as well as in other recent DES studies - an improvement that may be most pronounced in the subset of complex patients.

\section{Study limitations}

Because of the post hoc nature of this analysis, the results should be considered as hypothesis-generating. Off-label criteria of DES are "moving targets" and may differ between DES types. For that reason, for the entire study population we applied a definition that was recently used by another research group ${ }^{11}$. In the present study patients with on-label DES use showed a higher prevalence of arterial hypertension and hypercholesterolaemia, for which we do not have an explanation. The TWENTE trial enrolled patients with limited exclusion criteria but no acute STEMI; therefore, our results may not be extrapolated to the setting of STEMI ${ }^{7}$. Nevertheless, the vast majority of patients were complex and the rate of NSTE-ACS was high. All patients were treated in a highvolume tertiary PCI centre by five experienced interventional cardiologists who applied stent post-dilation in the vast majority of cases; therefore, generalisation of the findings may be limited in other settings.

\section{Conclusion}

Despite differences in risk profile, patients with off-label DES use did not differ significantly from patients with on-label DES use in clinical endpoints other than PMI. These largely positive findings underline the favourable safety profile of second-generation DES.

\section{Impact on daily practice}

Off-label patients of the TWENTE trial had two-year event rates for cardiac death, target vessel revascularisation and stent thrombosis that were comparable to those of patients with onlabel indications for drug-eluting stent (DES) use. Off-label use of contemporary DES was associated with a higher rate of periprocedural myocardial infarction, but only a minority of these patients developed maximum creatine kinase levels of more than 5 times the upper limit of normal. Overall, our findings show that PCI with these DES is feasible and safe in patients with off-label DES use. Therefore, in clinical practice with implantation of second-generation DES, distinction between patients with off-label and on-label indication for DES use may be of limited value.

\section{Funding}

This study is an investigator-initiated study that was performed without funding. The randomised TWENTE trial was an investigator-initiated study, supported by equal unrestricted grants from Abbott Vascular and Medtronic. The institution has also received research grants provided by Biotronik and Boston Scientific.

\section{Conflict of interest statement}

C. von Birgelen is consultant to and has received lecture fees or travel expenses from Abbott Vascular, Boston Scientific, and Medtronic. He has also received travel expenses from Biotronik and lecture fees from Biotronik and MSD. All the other authors have no conflicts of interest to declare.

\section{References}

1. Bauer T, Nienaber CA, Akin I, Kuck KH, Hochadel M, Senges J, Fetsch T, Tebbe U, Willich SN, Stumpf J, Sabin GV, Silber S, Richardt G, Zahn R; DES.DE Study Group. Comparison between on-label versus off-label use of drug-eluting coronary stents in clinical practice: results from the German DES. DE-Registry. Clin Res Cardiol. 2011;100:701-9.

2. Grines CL. Off-label use of drug-eluting stents putting it in perspective. J Am Coll Cardiol. 2008;51:615-7.

3. Beohar N, Davidson CJ, Kip KE, Goodreau L, Vlachos HA, Meyers SN, Benzuly KH, Flaherty JD, Ricciardi MJ, Bennett CL, Williams DO. Outcomes and complications associated with offlabel and untested use of drug-eluting stents. JAMA. 2007;297: 1992-2000.

4. Win HK, Caldera AE, Maresh K, Lopez J, Rihal CS, Parikh MA, Granada JF, Marulkar S, Nassif D, Cohen DJ, Kleiman NS; EVENT Registry Investigators. Clinical outcomes and stent thrombosis following off-label use of drug-eluting stents. JAMA. 2007;297:2001-9.

5. Basalus MW, Ankone MJ, van Houwelingen GK, de Man FH, von Birgelen C. Coating irregularities of durable polymer-based drug-eluting stents as assessed by scanning electron microscopy. EuroIntervention. 2009;5:157-65. 
6. Serruys PW, Silber S, Garg S, van Geuns RJ, Richardt G, Buszman PE, Kelbaek H, van Boven AJ, Hofma SH, Linke A, Klauss V, Wijns W, Macaya C, Garot P, DiMario C, Manoharan G, Kornowski R, Ischinger T, Bartorelli A, Ronden J, Bressers M, Gobbens P, Negoita M, van Leeuwen F, Windecker S. Comparison of zotarolimus-eluting and everolimus-eluting coronary stents. N Engl J Med. 2010;363:136-46.

7. von Birgelen C, Basalus MW, Tandjung K, van Houwelingen KG, Stoel MG, Louwerenburg JH, Linssen GC, Said SA, Kleijne MA, Sen H, Lowik MM, van der Palen J, Verhorst PM, de Man FH. A randomized controlled trial in secondgeneration zotarolimus-eluting Resolute stents versus everolimuseluting Xience V stents in real-world patients: the TWENTE trial. $J$ Am Coll Cardiol. 2012;59:1350-61.

8. Latib A, Ferri L, Ielasi A, Godino C, Chieffo A, Magni V, Bassanelli G, Sharp AS, Gerber R, Michev I, Carlino M, Airoldi F, Sangiorgi GM, Montorfano M, Colombo A. Clinical outcomes after unrestricted implantation of everolimus-eluting stents. JACC Cardiovasc Interv. 2009;2:1219-26.

9. Galasso G, Piccolo R, Cassese S, Esposito G, Cirillo P, Leosco D, Rapacciuolo A, Sirico D, De Biase C, Niglio T, Piscione F. Unrestricted use of endeavor resolute zotarolimus-eluting stent in daily clinical practice: a prospective registry. J Invasive Cardiol. 2012;24:251-5.

10. Romagnoli E, Godino C, Ielasi A, Gasparini G, Tzifos V, Sciahbasi A, Lioy E, Presbitero P, Colombo A, Sangiorgi G. Resolute Italian study in all comers: immediate and one-year outcomes. Catheter Cardiovasc Interv. 2012;79:567-74.

11. Stefanini GG, Serruys PW, Silber S, Khattab AA, van Geuns RJ, Richardt G, Buszman PE, Kelbaek H, van Boven AJ, Hofma SH, Linke A, Klauss V, Wijns W, Macaya C, Garot P, Di Mario C, Manoharan G, Kornowski R, Ischinger T, Bartorelli AL, Gobbens P, Windecker S. The impact of patient and lesion complexity on clinical and angiographic outcomes after revascularization with zotarolimus- and everolimus-eluting stents: a substudy of the RESOLUTE All Comers Trial (a randomized comparison of a zotarolimus-eluting stent with an everolimus-eluting stent for percutaneous coronary intervention). J Am Coll Cardiol. 2011;57: 2221-32.

12. Tandjung K, Sen H, Lam MK, Basalus MW, Louwerenburg JH, Stoel MG, van Houwelingen KG, de Man FH, Linssen GC, Said SA, Nienhuis MB, Lowik MM, Verhorst PM, van der Palen J, von Birgelen C. Clinical outcome following stringent discontinuation of dual antiplatelet therapy after 12 months in real-world patients treated with second-generation zotarolimus-eluting Resolute and everolimus-eluting Xience V stents: 2-year follow-up of the randomized TWENTE trial. J Am Coll Cardiol. 2013;61:2406-16.

13. Sen H, Tandjung K, Basalus MW, Lowik MM, van Houwelingen GK, Stoel MG, Louwerenburg HW, de Man FH, Linssen GC, Nijhuis R, Nienhuis MB, Verhorst PM, van der Palen J, von Birgelen C. Comparison of eligible non-enrolled patients and the randomised TWENTE trial population treated with Resolute and Xience V drug-eluting stents. EuroIntervention. 2012;8:664-71.
14. Vranckx P, Cutlip DE, Mehran R, Kint PP, Silber S, Windecker S, Serruys PW. Myocardial infarction adjudication in contemporary all-comer stent trials: balancing sensitivity and specificity. Addendum to the historical MI definitions used in stent studies. EuroIntervention. 2010;5:871-4.

15. Cutlip DE, Windecker S, Mehran R, Boam A, Cohen DJ, van Es GA, Steg PG, Morel MA, Mauri L, Vranckx P, McFadden E, Lansky A, Hamon M, Krucoff MW, Serruys PW; Academic Research Consortium. Clinical end points in coronary stent trials: a case for standardized definitions. Circulation. 2007;115: 2344-51.

16. Prasad A, Herrmann J. Myocardial infarction due to percutaneous coronary intervention. N Engl J Med. 2011;364:453-64.

17. Jeremias A, Ruisi CP, Kirtane AJ, Lee T, Sylvia B, Pinto DS, Ho KK, Cutlip DE, Carrozza JP Jr, Cohen DJ. Differential outcomes after sirolimus-eluting stent implantation: comparing onlabel versus off-label patients in the 'real world'. Coron Artery Dis. 2008; 19:111-5.

18. Lasala JM, Cox DA, Lewis SJ, Tadros PN, Haas RC, Schweiger MJ, Chhabra A, Untereker WJ, Starzyk RM, Mascioli SR, Dawkins KD, Baim DS. Expanded use of the TAXUS Express Stent: two-year safety insights from the 7,500 patient ARRIVE Registry programme. EuroIntervention. 2009;5: 67-77.

19. Mehilli J, Richardt G, Valgimigli M, Schulz S, Singh A, Abdel-Wahab M, Tiroch K, Pache J, Hausleiter J, Byrne RA, Ott I, Ibrahim T, Fusaro M, Seyfarth M, Laugwitz KL, Massberg S, Kastrati A; ISAR-LEFT-MAIN 2 Study Investigators. Zotarolimusversus everolimus-eluting stents for unprotected left main coronary artery disease. J Am Coll Cardiol. 2013;62:2075-82.

20. Stefanini GG, Kalesan B, Serruys PW, Heg D, Buszman P, Linke A, Ischinger T, Klauss V, Eberli F, Wijns W, Morice MC, Di Mario C, Corti R, Antoni D, Sohn HY, Eerdmans P, van Es GA, Meier B, Windecker S, Jüni P. Long-term clinical outcomes of biodegradable polymer biolimus-eluting stents versus durable polymer sirolimus-eluting stents in patients with coronary artery disease (LEADERS): 4 year follow-up of a randomised non-inferiority trial. Lancet. 2011;378:1940-8.

21. Danzi GB, Chevalier B, Urban P, Fath-Ordoubadi F, Carrie D, Wiemer M, Serra A, Wijns W, Kala P, Stabile A, Ruigomez JG, Sagic D, Laanmets P, Strupp G, West N, Paunovic D; NOBORI 2 Investigators. Clinical performance of a drug-eluting stent with a biodegradable polymer in an unselected patient population: the NOBORI 2 study. EuroIntervention. 2012;8:109-16.

22. Nienhuis MB, Ottervanger JP, Bilo HJ, Dikkeschei BD, Zijlstra F. Prognostic value of troponin after elective percutaneous coronary intervention: a meta-analysis. Catheter Cardiovasc Interv. 2008;71:318-24.

23. Prasad A, Singh M, Lerman A, Lennon RJ, Holmes DR Jr, Rihal CS. Isolated elevation in troponin $\mathrm{T}$ after percutaneous coronary intervention is associated with higher long-term mortality. J Am Coll Cardiol. 2006;48:1765-70. 
24. Ioannidis JP, Karvouni E, Katritsis DG. Mortality risk conferred by small elevations of creatine kinase-MB isoenzyme after percutaneous coronary intervention. J Am Coll Cardiol. 2003;42:1406-11.

25. Ellis SG, Chew D, Chan A, Whitlow PL, Schneider JP, Topol EJ. Death following creatine kinase-MB elevation after coronary intervention: identification of an early risk period: importance of creatine kinase-MB level, completeness of revascularization, ventricular function, and probable benefit of statin therapy. Circulation. 2002;106:1205-10.

26. Prasad A, Gersh BJ, Bertrand ME, Lincoff AM, Moses JW, Ohman EM, White HD, Pocock SJ, McLaurin BT, Cox DA,
Lansky AJ, Mehran R, Stone GW. Prognostic significance of periprocedural versus spontaneously occurring myocardial infarction after percutaneous coronary intervention in patients with acute coronary syndromes: an analysis from the ACUITY (Acute Catheterization and Urgent Intervention Triage Strategy) trial. J Am Coll Cardiol. 2009;54:477-86.

27. Jeremias A, Baim DS, Ho KK, Chauhan M, Carrozza JP Jr, Cohen DJ, Popma JJ, Kuntz RE, Cutlip DE. Differential mortality risk of postprocedural creatine kinase-MB elevation following successful versus unsuccessful stent procedures. J Am Coll Cardiol. 2004;44:1210-4. 